\title{
Readmission and reoperation for hydrocephalus: a population-based analysis across the spectrum of age
}

\author{
Allison LeHanka' and Joseph Piatt, MD, MAS ${ }^{2-4}$ \\ 'University of Notre Dame, Notre Dame, Indiana; ${ }^{2}$ Nemours/Alfred I. duPont Hospital for Children, Wilmington, Delaware; \\ and Departments of ${ }^{3}$ Neurological Surgery and ${ }^{4}$ Pediatrics, Sidney Kimmel Medical College, Thomas Jefferson University, \\ Philadelphia, Pennsylvania
}

OBJECTIVE Hydrocephalus is a common, chronic illness that generally requires lifelong, longitudinal, neurosurgical care. Except at select research centers, surgical outcomes in the United States have not been well documented. Comparative outcomes across the spectrum of age have not been studied.

METHODS Data were derived for the year 2015 from the Nationwide Readmissions Database, a product of the Healthcare Cost and Utilization Project of the Agency for Healthcare Research and Quality. In this data set patients are assigned state-specific codes that link repeated discharges through the calendar year. Discharges with diagnostic codes for hydrocephalus were extracted, and for each patient the first discharge defined the index admission. The study event was readmission. Observations were censored at the end of the year. In a similar fashion the first definitive surgical procedure for hydrocephalus was defined as the index operation, and the study event was reoperation for hydrocephalus or complications. Survival without readmission and survival without reoperation were analyzed using life tables and KaplanMeier plots.

RESULTS Readmission rates at 30 days ranged between $15.6 \%$ and $16.8 \%$ by age group without significant differences. After the index admission the first readmission alone generated estimated hospital charges of $\$ 2.25$ billion nationwide. Reoperation rates at 30 days were $34.9 \%$ for infants, $39.2 \%$ for children, $47.4 \%$ for adults, and $32.4 \%$ for elders. These differences were highly significant. More than 3 times as many index operations were captured for adults and elders as for infants and children. Estimated 1 -year reoperation rates were $74.2 \%$ for shunt insertion, $63.9 \%$ for shunt revision, but only $34.5 \%$ for endoscopic third ventriculostomy. Univariate associations with survival without readmission and survival without reoperation are presented.

CONCLUSIONS In the United States hydrocephalus is predominantly a disease of adults. Surgical outcomes in this population-based study were substantially worse than outcomes reported from research centers. High reoperation rates after CSF shunt surgery accounted for this discrepancy.

https://thejns.org/doi/abs/10.3171/2020.3.JNS20528

KEYWORDS adults; children; hydrocephalus; readmission; reoperation

$\mathrm{T}$ HE etiologies of hydrocephalus vary greatly by age. Hydrocephalus as an entity has been the focus of intense scientific and clinical research in pediatric neurosurgical practice, but in adult practice it has received attention mostly as a complication of other disease processes, such as cerebrovascular disease, trauma, or neoplasia, or as the distinct syndrome of idiopathic normal pressure hydrocephalus. The current work is a global, comparative overview of the surgical management of hydrocephalus across the spectrum of age. It is global in a second sense as well: it is population based, so it captures the experiences of unselected patients treated in all different neurosurgical practice environments in the United States.

\section{Methods}

Data were extracted from the Nationwide Readmissions Database (NRD) for 2015, created by the Healthcare

ABBREVIATIONS CCS = Clinical Classification Software; $C P C=$ choroid plexus coagulation; $E T V=$ endoscopic third ventriculostomy; NRD = Nationwide Readmissions Database. 


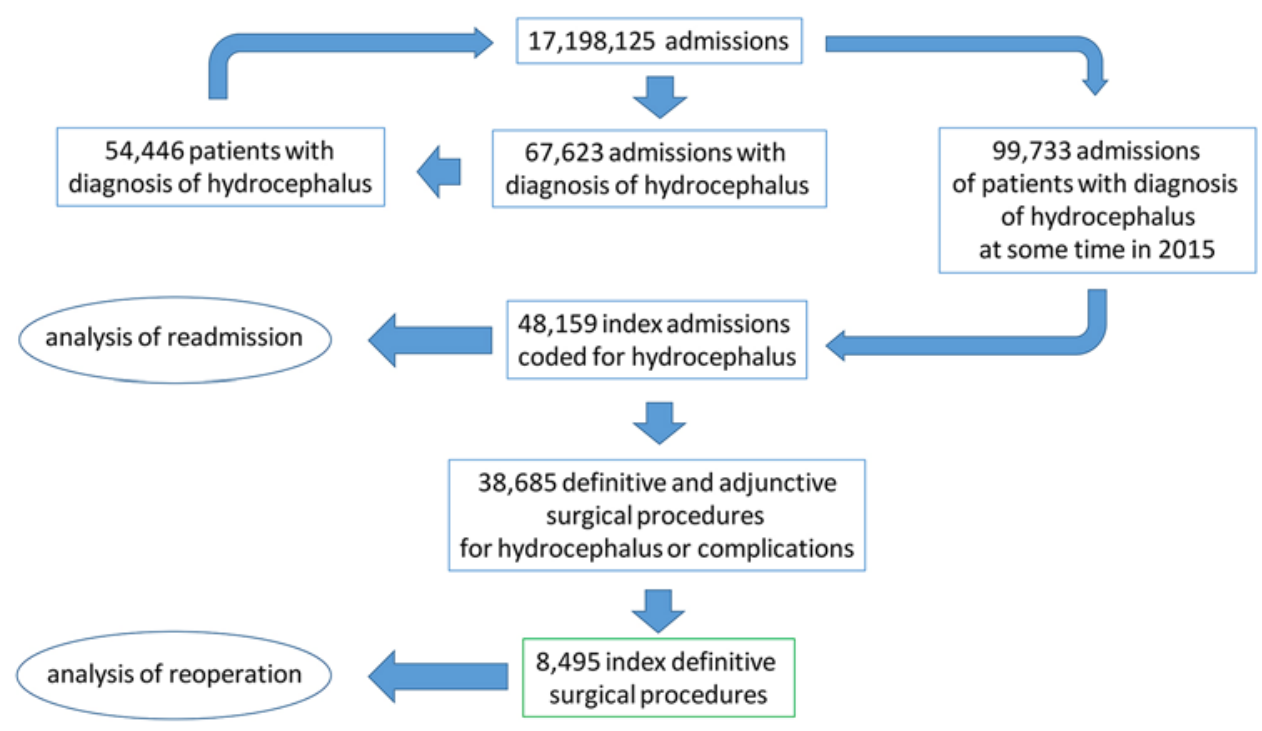

FIG. 1. Workflow for sorting and organization of observations for survival analysis. Figure is available in color online only.

Cost and Utilization Project of the Agency for Healthcare Research and Quality. This NRD captures discharge data from all acute care hospitalizations in the 27 states in the United States that participated in 2015. Patients are assigned state-specific codes that link repeated discharges through the calendar year. Readmission to hospitals in another state is not captured. The NRD has estimated this effect on 30-day readmission rate for the 247 Clinical Classification Software (CCS) principal diagnosis categories, and for $90 \%$ of categories the discrepancy is less than $5 \% .{ }^{1}$ Also not captured are discharges after hospitalizations that run into the following calendar year. For example, if a patient were discharged on January 1,2015, this admission would be captured in the 2015 data set regardless of when it began. But if the same patient were readmitted on January 2, 2015, and then discharged sometime in 2016, the readmission would not be captured. These 2 features introduce a favorable bias in analysis of survival in this data set. The NRD provides weights for extrapolation to nationwide annual incidences, but except where specified, unweighted data were studied as a large convenience sample.

Age was categorized as "infant" (less than 1 year of age), "child" (1-18 years of age), "adult" (19-55 years of age), and "elder" (more than 55 years of age). Categories of payer were collapsed as follows: "Medicare," "low income" (Medicaid, self-pay, and no charge), and "commercial" (private or other).

Organization of the data is depicted in Fig. 1. First extracted were discharges with diagnostic codes for hydrocephalus. Between the third and fourth quarters of 2015, the NRD transitioned from ICD-9 to ICD-10 diagnostic and procedural codes, and both sets of codes were searched. All distinct patients discharged in 2015 with diagnostic codes for hydrocephalus were identified, and as a second step all of these patients' discharge records were extracted. Finally, discharges that preceded the first diagnosis of hydrocephalus were discarded-the first admis- sion with a diagnostic code for hydrocephalus was considered the "index" admission for each patient. For analysis of time to readmission, readmission was considered the study event, and the duration from previous discharge to readmission was considered the study interval. Death was not considered a study event, because it can appear in this data set only as the termination of a readmission. Index admissions that ended in death were excluded from analysis. If the patient was alive at discharge and if no subsequent hospitalization was recorded, the observation was censored at the end of the year.

From this readmission data set were extracted discharges with procedural codes for operations to treat hydrocephalus and its complications. Both ventricular and lumbar shunts were captured. Shunt insertions and revisions and endoscopic third ventriculostomies (ETVs) without or with choroid plexus coagulation (CPC) were considered "definitive" procedures. Ventricular reservoirs, ventriculosubgaleal shunts, other CSF drains, subdural shunts and other procedures to drain subdural hemorrhage, and removal of shunts were considered "adjunctive" procedures. From these discharge records each operation for hydrocephalus was extracted to be considered as a distinct observation. The first procedural code for a definitive operation was considered the "index" procedure for each patient. This data set was analyzed for time to reoperation. The study event was the next operation for hydrocephalus or a complication of hydrocephalus, including adjunctive procedures. Because the NRD includes the day of each procedure in relation to the day of admission, the number of days between the study procedure and the study event were extracted as the study interval. Death was not considered a study event. Observations of patients who died were censored on the day of death. If the patient was alive at discharge and if no subsequent operation was recorded, the observation was censored at the end of the year.

A complete case analysis was performed. Missing data for the day of a procedure made identification of the se- 
quence of that patient's procedures impossible, so all intervals between procedures for that patient were defined as missing.

Survival plots were prepared by the Kaplan-Meier method. Estimated survivals at 30 days, 90 days, and 1 year were estimated by life tables for the first observation captured for each study patient. Survivals were compared using the log-rank test. For the covariates of greatest interest-age group and operation type - the assumption of proportional hazards was not met, so Cox regressions and hazard ratios are not presented. A risk of type 1 error less than 0.05 was considered significant. Data were analyzed with SAS Enterprise Guide version 7.1 (SAS Corp.).

This project was judged not to be human subject research by the Nemours Institutional Review Board.

\section{Results \\ Readmission}

Admissions that ended in death $(11.6 \%$ of all first admissions coded for hydrocephalus) were excluded from analysis: $8.4 \%$ among admissions of infants; $1.7 \%$ among children; $10.1 \%$ among adults, and $14.1 \%$ among elders.

Readmission rates at 30 days, 90 days, and 1 year after the index admission are presented in Table 1 by age group. Differences in readmission rates by age group did not attain statistical significance (log-rank test; $\mathrm{p}=0.0750)$, and they were of negligible clinical significance. Univariate associations of other selected factors with risk of readmission appear in Table 1 as well. Although some associations were highly significant because of large numbers of observations, effect sizes were small.

CCS diagnoses are available for the first 3 quarters of 2015. These diagnoses are listed in order of descending importance. For each age group the 10 most frequent leading diagnoses for the first readmission after the index admission are presented in Table 2.

Extrapolated to the nationwide population base, total charges for the first readmission after the first discharge coded for hydrocephalus were $\$ 2.25$ billion.

\section{Reoperation}

Observations were censored at the death of the patient. After the first definitive surgical procedure $3.4 \%$ of patients died prior to any other surgery: $2.5 \%$ of infants; $0.7 \%$ of children; $3.4 \%$ of adults; and $4.0 \%$ of elders.

Reoperation rates at 30 days, 90 days, and 1 year after the index operation for hydrocephalus are presented in Table 3 by age group, by operation type, and by other selected covariates. Early reoperation rates were highest for the adult group and lowest for the elder group. Highly significant differences were observed between shunt surgery and ETV as well. Kaplan-Meier plots stratified by age and operation appear in Fig. 2.

\section{Discussion}

\section{Readmission}

There has been very little study of readmission rates for patients with hydrocephalus. Chern et al. recorded an all-cause, 30-day readmission rate of $16.5 \%$ after shunt surgery at a large urban children's hospital. ${ }^{2}$ Three-quarters of these admissions were related in some way to the preceding shunt surgery, but only half of them entailed shunt revision. Curiously, Donoho et al. reported precisely the same postsurgical, 30-day readmission rate, $16.5 \%$, in a study of adult patients from the NRD. ${ }^{3}$ Common reasons for readmission were urinary tract infection, mechanical complication of a CNS device, and seizures. The current study is in remarkable agreement with these observations, even though it adopted a different starting point, discharge after any admission coded for a diagnosis of hydrocephalus.

The estimated charges attributed to first readmissions in 2015 were well over \$2 billion, so measures to prevent readmissions for patients with hydrocephalus have potential to reap savings for the healthcare system. Unfortunately, analyses of demographic factors predictive of readmission were unhelpful in focusing such efforts because of small effect sizes. The lower risk of readmission after elective admission requires no comment. The low risk of readmission enjoyed by patients from rural areas at smaller, nonmetropolitan hospitals probably reflects the concentration of more complex cases in urban teaching institutions. The uniformity of readmission rates across demographic, socioeconomic, and institutional categories suggests that the determining factors are specific to the clinical circumstances of individual patients.

CCS categories for reasons for admission were not coded for all admissions, and many had more than one code. Only the leading code was extracted, and only qualitative observations were possible. Among reasons for admission, "complication of device, implant, or graft" was prominent among infants, children, and adults, so neurosurgeons have a self-evident technical role in managing this chronic disease. "Epilepsy, convulsions" figured prominently in all age groups and represents a target for disease management. Not to be overlooked is the fact that the "elder" age group accounted for more first admissions and readmissions than all other age groups combined. Hydrocephalus is likely to be a marker for medical fragility among the elderly. Whether it has independent predictive value in the company of other commonly used markers for intensive case management in this age group is a question for further research.

\section{Reoperation}

The current study confirmed previously identified risk factors for early reoperation and identified some that have not been discussed explicitly. The greater risk of early failure after shunt revision than after initial shunt insertion is established in the research literature. ${ }^{4-7}$ In the current data the survival plots for insertion and revision crossed at approximately 120 days. This crossing of the plots was present among children, adults, and elders. Only among infants was survival of shunt insertions superior to shunt revisions (data not shown). The explanation for this contrast with the observations from other settings is not clear. There was early crossing of survival plots by age group as well, although at a later time point children and elders had distinctly better outcomes than adults and infants. So far as we are aware, there has been 
TABLE 1. Readmission rates as estimated percentages (standard errors of the estimate) calculated by life table and compared by the log-rank test

\begin{tabular}{|c|c|c|c|c|c|c|}
\hline \multirow[b]{2}{*}{ Factor } & \multirow[b]{2}{*}{ Category } & \multirow[b]{2}{*}{ No. } & \multicolumn{3}{|c|}{ Readmission Rate } & \multirow[b]{2}{*}{ p Value } \\
\hline & & & 30-Day & 60-Day & $1-Y r$ & \\
\hline \multirow[t]{5}{*}{ Age group } & & & & & & 0.0750 \\
\hline & Infants & 1143 & $16.8(1.1)$ & $31.9(1.5)$ & $50.8(2.0)$ & \\
\hline & Children & 5675 & $15.6(0.5)$ & $28.5(0.6)$ & $48.6(0.9)$ & \\
\hline & Adults & 13,091 & $16.7(0.3)$ & $28.5(0.4)$ & $45.8(0.6)$ & \\
\hline & Elders & 28,250 & $15.9(0.2)$ & $28.4(0.3)$ & $47.5(0.4)$ & \\
\hline \multirow[t]{3}{*}{ Sex } & & & & & & $<0.0001$ \\
\hline & Female & 22,958 & $15.3(0.2)$ & $27.3(0.3)$ & $45.9(0.4)$ & \\
\hline & Male & 25,201 & $16.8(0.2)$ & $29.6(0.3)$ & $48.5(0.4)$ & \\
\hline \multirow[t]{4}{*}{ Payer } & & & & & & $<0.0001$ \\
\hline & Low income & 10,799 & $16.2(0.4)$ & $28.7(0.5)$ & $47.6(0.6)$ & \\
\hline & Commercial & 12,457 & $15.8(0.3)$ & $27.0(0.4)$ & $42.7(0.6)$ & \\
\hline & Medicare & 24,852 & $16.2(0.2)$ & $29.2(0.3)$ & $49.3(0.4)$ & \\
\hline \multirow[t]{5}{*}{ Median income, home zip code } & & & & & & 0.1109 \\
\hline & 1st quartile & 12,966 & $16.1(0.3)$ & $29.3(0.4)$ & $47.7(0.5)$ & \\
\hline & 2nd quartile & 11,200 & $16.3(0.4)$ & $28.9(0.5)$ & $47.9(0.6)$ & \\
\hline & 3rd quartile & 11,718 & $15.6(0.3)$ & $27.4(0.4)$ & $46.6(0.6)$ & \\
\hline & 4th quartile & 11,528 & $16.3(0.4)$ & $28.4(0.4)$ & $46.8(0.6)$ & \\
\hline \multirow[t]{3}{*}{ Population density } & & & & & & $<0.0001$ \\
\hline & High & 37,673 & $16.4(0.2)$ & $29.1(0.2)$ & $47.9(0.3)$ & \\
\hline & Low & 10,486 & $14.9(0.4)$ & $26.4(0.5)$ & $44.9(0.7)$ & \\
\hline \multirow[t]{3}{*}{ Admission type } & & & & & & $<0.0001$ \\
\hline & Elective & 8861 & $13.9(0.4)$ & $24.9(0.5)$ & $43.1(0.7)$ & \\
\hline & Not elective & 39,171 & $16.6(0.2)$ & $29.3(0.2)$ & $48.2(0.3)$ & \\
\hline \multirow[t]{3}{*}{ Admission day } & & & & & & 0.5351 \\
\hline & Weekday & 38,218 & $16.1(0.2)$ & $28.5(0.2)$ & $47.5(0.3)$ & \\
\hline & Weekend & 9941 & $16.2(0.4)$ & $28.7(0.5)$ & $46.4(0.7)$ & \\
\hline \multirow[t]{4}{*}{ Hospital control } & & & & & & 0.1707 \\
\hline & Government & 2358 & $16.1(0.4)$ & $28.0(0.6)$ & $45.5(0.8)$ & \\
\hline & Voluntary & 36,160 & $16.1(0.2)$ & $28.6(0.3)$ & $47.4(0.3)$ & \\
\hline & Proprietary & 4850 & $15.9(0.5)$ & $28.5(0.7)$ & $48.4(1.0)$ & \\
\hline \multirow[t]{4}{*}{ Hospital type } & & & & & & 0.3009 \\
\hline & Nonteaching & 8443 & $15.6(0.4)$ & $28.7(0.5)$ & $48.8(0.7)$ & \\
\hline & Teaching & 38,207 & $16.3(0.2)$ & $28.5(0.2)$ & $46.9(0.3)$ & \\
\hline & Nonmetro & 1509 & $14.6(0.9)$ & $27.0(1.2)$ & $47.2(1.7)$ & \\
\hline \multirow[t]{4}{*}{ Hospital bed size } & & & & & & 0.0918 \\
\hline & Small & 4528 & $14.8(0.5)$ & $26.9(0.7)$ & $46.7(1.0)$ & \\
\hline & Medium & 10,385 & $15.5(0.4)$ & $28.4(0.5)$ & $47.0(0.7)$ & \\
\hline & Large & 33,246 & $16.4(0.2)$ & $28.8(0.3)$ & $47.4(0.4)$ & \\
\hline
\end{tabular}

Nonmetro $=$ nonmetropolitan .

no previous epidemiological study across the spectrum of age with which to compare these observations. Less well documented in the literature but unsurprising is the effect of poverty as reflected in insurance coverage. The associations with hospital control and teaching status probably reflect concentration of complex cases at urban academic centers. The adverse effects of nonelective admission and weekend admission suggest deficiencies in staffing, adherence to protocols, and-possibly-supervision of trainees that might be addressed by quality improvement initiatives. ${ }^{8}$

A comprehensive survey of the actuarial literature on the durability of the surgical treatment of hydrocephalus is beyond the scope of this discussion. What is notable is how much worse are the short-term results of shunt surgery developed in the current study than historical results 
TABLE 2. The 10 most common leading diagnoses in the first readmission after the index admission, listed in descending order

\begin{tabular}{|c|c|c|c|}
\hline Infants & Children & Adults & Elders \\
\hline $\begin{array}{l}\text { Complication of device, implant, or } \\
\text { graft (15\%) }\end{array}$ & $\begin{array}{l}\text { Complication of device, implant, or } \\
\text { graft }(21 \%)\end{array}$ & $\begin{array}{l}\text { Complication of device, implant, or } \\
\text { graft }(16 \%)\end{array}$ & Septicemia (13\%) \\
\hline $\begin{array}{l}\text { Nervous system congenital anoma- } \\
\text { lies (14\%) }\end{array}$ & Epilepsy, convulsions (9\%) & Septicemia (8\%) & $\begin{array}{l}\text { Other hereditary \& degenerative } \\
\text { nervous system conditions (10\%) }\end{array}$ \\
\hline $\begin{array}{l}\text { Other hereditary \& degenerative } \\
\text { nervous system conditions (13\%) }\end{array}$ & $\begin{array}{l}\text { Complications of surgical proce- } \\
\text { dures or medical care }(6 \%)\end{array}$ & $\begin{array}{l}\text { Other hereditary \& degenerative } \\
\text { nervous system conditions (6\%) }\end{array}$ & $\begin{array}{l}\text { Complication of device, implant, or } \\
\text { graft }(6 \%)\end{array}$ \\
\hline Epilepsy, convulsions (6\%) & $\begin{array}{l}\text { Maintenance chemotherapy or } \\
\text { radiation therapy }(6 \%)\end{array}$ & $\begin{array}{l}\text { Complications of surgical procedures } \\
\text { or medical care }(6 \%)\end{array}$ & Acute cerebrovascular disease (4\%) \\
\hline Acute bronchitis (5\%) & $\begin{array}{l}\text { Other hereditary \& degenerative } \\
\text { nervous system conditions (4\%) }\end{array}$ & Epilepsy, convulsions (4\%) & Urinary tract infections (4\%) \\
\hline $\begin{array}{l}\text { Respiratory failure; insufficiency } \\
\quad(3 \%)\end{array}$ & $\begin{array}{l}\text { Cancer of the brain or nervous } \\
\text { system }(3 \%)\end{array}$ & Other nervous system disorders (4\%) & Pneumonia (3\%) \\
\hline $\begin{array}{l}\text { Other nervous system disorders } \\
\text { (3\%) }\end{array}$ & $\begin{array}{l}\text { Respiratory failure; insufficiency } \\
\text { (3\%) }\end{array}$ & $\begin{array}{l}\text { Cancer of the brain or nervous sys- } \\
\text { tem }(3 \%)\end{array}$ & $\begin{array}{l}\text { Other nervous system disorders } \\
\text { (3\%) }\end{array}$ \\
\hline Pneumonia (3\%) & Pneumonia (3\%) & Acute cerebrovascular disease (2\%) & $\begin{array}{l}\text { Acute \& unspecified renal failure } \\
(2 \%)\end{array}$ \\
\hline Intestinal infection (3\%) & $\begin{array}{l}\text { Other nervous system disorders } \\
\text { (3\%) }\end{array}$ & Secondary malignancies (2\%) & $\begin{array}{l}\text { Complications of surgical proce- } \\
\text { dures or medical care ( } 2 \%)\end{array}$ \\
\hline Other congenital anomalies (3\%) & $\begin{array}{l}\text { Other upper respiratory infections } \\
\text { (2\%) }\end{array}$ & Headache, including migraine (2\%) & Epilepsy, convulsions (2\%) \\
\hline
\end{tabular}

from research centers, registries, and prospective trials. Highly selected contributions from this literature are reviewed below.

Setting a high bar for quality are a number of tightly clustered 30-day reoperation rates from several modern, prospective data sets. In 2014 Al-Tamimi et al. reported 30-day and 12-month reoperation rates for new shunts of $12.9 \%$ and $28.8 \%$, respectively, from a British multicenter pediatric shunt registry. ${ }^{4}$ These authors noted the tight clustering of 30-day failure rates in their own study and in the North American Shunt Design Trial and Endoscopic Shunt Insertion Trial of the 1990s, where 30-day failure rates were $14 \%$ and $16 \%$, respectively. ${ }^{9,10}$ This observation was confirmed by reports of 30-day rates in the $13.5 \%-14.1 \%$ range in studies of data from the National Surgical Quality Improvement Program-Pediatrics in the United States.,11 A very recent report from Leeds cites 30day failure rates of $17.7 \%$ and $21.5 \%$ among children and adults, respectively. ${ }^{5}$ Chern et al. reported an even lower rate, $8.9 \%$, but these authors did not count reoperations during the index admission. ${ }^{2}$ The current study extracted all operations from every admission. The similarity of 30day reoperation rates from different decades on different continents has focused interest in this statistic as a possible quality metric in pediatric shunt surgery. This clustering of rates is roughly half the 30-day reoperation rate observed in the current study.

In a population-based study comparable to the one reported here, Cochrane and Kestle analyzed records of CSF shunt surgery for pediatric hydrocephalus between 1989 and 2001 in a comprehensive federal database capturing all inpatient activity in English-speaking Canada. ${ }^{12,13}$ Despite a high degree of neurosurgical regionalization compared to the United States, many surgeons and many hospitals that provided services to children had very low caseloads. ${ }^{12}$ Shunt survival and infection rates were associated inversely with surgeon experience as measured both by years in practice and by caseload. ${ }^{12,13}$ Six-month reoperation rates varied between $31 \%$ and $38 \%$ depending on surgeon experience. The Methods section does not make clear whether other procedures besides shunt revision, such as insertion of a CSF drain, drainage of subdural hemorrhage, or shunt removal without replacement, were captured as events in this analysis.

In a 9-year study using employer-sponsored insurance claims for patients 19 years of age or younger, Lam et al. reported a long-term overall ETV success rate among children of $63 \% .{ }^{14}$ In a multivariate analysis only age and a history of previous shunt surgery were predictive. Methods differed from the current study in several respects: the observations were limited to commercially insured patients. Furthermore, the analysis seems not to have captured reoperations during the index admission. Nevertheless, these results are in remarkable agreement with the observations of the current study.

Donoho et al. drew on 5 years of data from the NRD to study readmission among adults treated surgically for hydrocephalus, but their methods differed from those of the current study. ${ }^{3}$ They excluded patients who required more than one operation for hydrocephalus during the index admission, and they took readmission for surgery as the event for survival analysis. Thus, their results seem favorable compared to the current study-among patients who had 6 months of follow-up, the rate of readmission for shunt surgery was only $9.2 \%$. How this calculation was performed was not stated clearly. It seemed to have excluded patients who were censored due to loss of followup before 6 months, in which case it was not an actuarial 
TABLE 3. Reoperation rates as estimated percentages (standard errors of the estimate) calculated by life table and compared by the log-rank test

\begin{tabular}{|c|c|c|c|c|c|c|}
\hline \multirow[b]{2}{*}{ Factor } & \multirow[b]{2}{*}{ Category } & \multirow[b]{2}{*}{ No. } & \multicolumn{3}{|c|}{ Reoperation Rate } & \multirow[b]{2}{*}{ p Value } \\
\hline & & & 30-Day & 60-Day & $1-Y r$ & \\
\hline \multirow[t]{5}{*}{ Age group } & & & & & & $<0.0001$ \\
\hline & Infants & 347 & $43.5(2.8)$ & $63.7(2.8)$ & $78.6(3.0)$ & \\
\hline & Children & 1745 & $38.6(1.2)$ & $43.9(1.3)$ & $51.8(1.5)$ & \\
\hline & Adults & 3072 & $47.2(0.9)$ & $54.6(0.9)$ & $63.8(1.1)$ & \\
\hline & Elders & 3331 & $37.4(0.9)$ & $45.7(0.9)$ & $57.5(1.2)$ & \\
\hline \multirow[t]{5}{*}{ Operation } & & & & & & $<0.0001$ \\
\hline & Shunt insertion & 3406 & $38.1(1.0)$ & $49.1(1.2)$ & $74.2(2.1)$ & \\
\hline & Shunt revision & 4534 & $46.1(0.7)$ & $54.2(0.8)$ & $63.9(0.8)$ & \\
\hline & ETV & 1308 & $29.7(1.3)$ & $32.3(1.4)$ & $34.5(1.5)$ & \\
\hline & ETV-CPC & 32 & $79.4(7.2)$ & $87.6(6.2)$ & $95.9(5.2)$ & \\
\hline \multirow[t]{3}{*}{ Sex } & & & & & & 0.3166 \\
\hline & Female & 3880 & $42.4(0.8)$ & $49.5(0.8)$ & $60.3(1.0)$ & \\
\hline & Male & 4400 & $40.6(0.8)$ & $49.1(0.8)$ & $58.6(1.0)$ & \\
\hline \multirow[t]{4}{*}{ Payer } & & & & & & $<0.0001$ \\
\hline & Low income & 2496 & $45.0(1.0)$ & $52.0(1.0)$ & $61.9(1.2)$ & \\
\hline & Commercial & 2894 & $43.2(0.9)$ & $50.8(1.0)$ & $59.9(1.1)$ & \\
\hline & Medicare & 2882 & $36.6(0.9)$ & $45.4(1.0)$ & $57.0(1.3)$ & \\
\hline \multirow[t]{5}{*}{ Median income, home zip code } & & & & & & 0.2460 \\
\hline & 1st quartile & 2274 & $41.0(1.1)$ & $48.7(1.1)$ & $58.7(1.3)$ & \\
\hline & 2nd quartile & 1948 & $43.3(1.2)$ & $51.1(1.2)$ & $61.5(1.4)$ & \\
\hline & 3rd quartile & 2060 & $40.8(1.1)$ & $48.8(1.2)$ & $58.9(1.4)$ & \\
\hline & 4th quartile & 1875 & $40.4(1.2)$ & $48.5(1.2)$ & $58.6(1.5)$ & \\
\hline \multirow[t]{3}{*}{ Population density } & & & & & & 0.0744 \\
\hline & High & 6394 & $42.0(0.6)$ & $49.9(0.7)$ & $59.7(0.8)$ & \\
\hline & Low & 1862 & $39.6(1.2)$ & $46.9(1.2)$ & $58.2(1.5)$ & \\
\hline \multirow[t]{3}{*}{ Admission type } & & & & & & $<0.0001$ \\
\hline & Elective & 2646 & $23.0(0.8)$ & $30.9(1.0)$ & $47.6(1.4)$ & \\
\hline & Not elective & 5619 & $50.0(0.7)$ & $57.7(0.7)$ & $65.0(0.8)$ & \\
\hline \multirow[t]{3}{*}{ Admission day } & & & & & & $<0.0001$ \\
\hline & Weekday & 6889 & $39.5(0.6)$ & $47.6(0.6)$ & $58.6(0.8)$ & \\
\hline & Weekend & 1391 & $50.9(1.4)$ & $57.6(1.4)$ & $63.4(1.5)$ & \\
\hline \multirow[t]{4}{*}{ Hospital control } & & & & & & 0.0070 \\
\hline & Government & 1595 & $44.9(1.3)$ & $52.7(1.3)$ & $61.7(1.5)$ & \\
\hline & Voluntary & 6038 & $41.0(0.6)$ & $48.7(0.7)$ & $59.0(0.8)$ & \\
\hline & Proprietary & 647 & $37.9(2.0)$ & $45.8(2.1)$ & $57.1(2.6)$ & \\
\hline \multirow[t]{4}{*}{ Hospital type } & & & & & & 0.0182 \\
\hline & Nonteaching & 877 & $38.0(1.7)$ & $46.4(1.8)$ & $56.3(2.2)$ & \\
\hline & Teaching & 7333 & $41.9(0.6)$ & $49.7(0.6)$ & $59.9(0.7)$ & \\
\hline & Nonmetro & 70 & $36.1(5.8)$ & $38.0(6.0)$ & $46.9(7.8)$ & \\
\hline \multirow[t]{4}{*}{ Hospital bed size } & & & & & & 0.2079 \\
\hline & Small & 549 & $37.3(2.1)$ & $46.6(2.3)$ & $56.9(2.9)$ & \\
\hline & Medium & 1460 & $41.0(1.3)$ & $48.1(1.4)$ & $58.4(1.7)$ & \\
\hline & Large & 4089 & $41.9(0.6)$ & $49.8(0.7)$ & $59.8(0.8)$ & \\
\hline
\end{tabular}



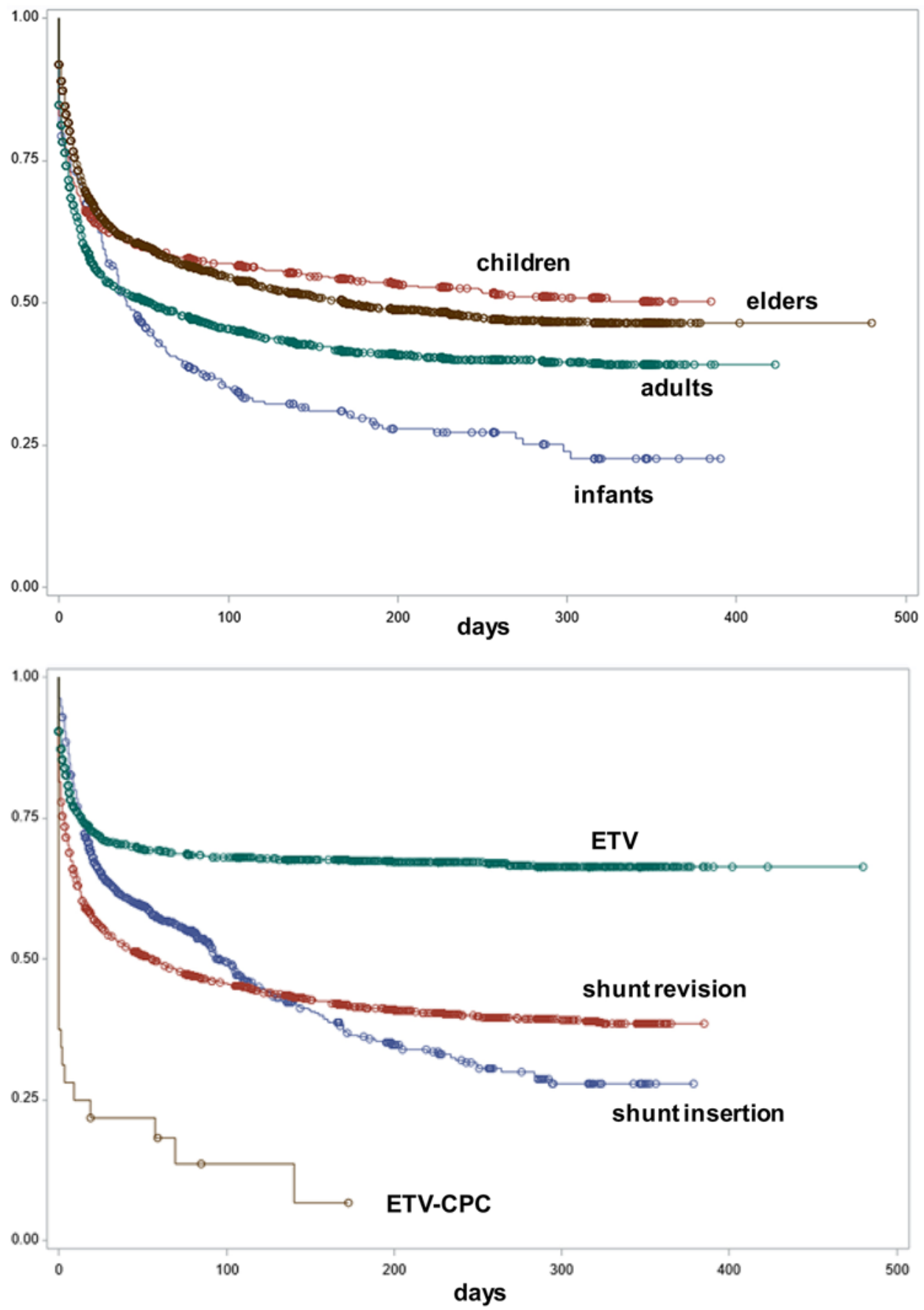

FIG. 2. Kaplan-Meier plots of estimated survival without reoperation after the index procedure stratified by age group (upper) and operation (lower). Empty circles represent censored observations. Figure is available in color online only.

calculation. In any event, it cannot be compared directly to any of the observations in the current study. This report by Donoho et al. appears to be the only population-based study of outcomes for adults with hydrocephalus.

Two observations from the current work have potentially important implications for neurosurgical training and practice. First, outcomes of shunt surgery for patients with hydrocephalus treated at unselected institutions are substantially worse than what might be expected based on a reading of the existing literature from major research cen- ters. Best practices developed at such centers seem not to be getting widespread dissemination and implementation. This putative failure may reflect insufficient inculcation of best practices among trainees. Second, adults and elders account for a great majority of the surgical procedures performed for hydrocephalus in the United States-almost 3 of 4 in the current analysis. Hydrocephalus is not only a pediatric disease, and competency in its surgical treatment is an obligation for all neurosurgeons, not for pediatric subspecialists alone. 


\section{Limitations of the Study}

As noted in the Methods section, the structure of the NRD introduces a favorable bias into survival analysis. Censoring cases at the death of the patient may have biased reoperation rates in a favorable direction as well.

The current study did not analyze the effect of etiology of hydrocephalus. Different mixes of etiologies undoubtedly account for much of the statistical effects of age. Neither the ICD-9 nor the ICD-10 system categorizes hydrocephalus usefully in clinical neurosurgical terms, and etiologies must be inferred from secondary diagnoses of uncertain reliability.

The unfavorable 30-day reoperation rates documented here focus attention on procedural codes. So far as we are aware, there has been no external validation of procedure codes for hydrocephalus in the NRD. Erroneous coding of adjunctive procedures, such as external ventricular drainage, as definitive procedures might have inflated early reoperation rates, because a true definitive procedure would have been likely to follow during the same admission. Because mutually exclusive sets of procedural codes were used to identify shunt insertion, shunt revision, and ETV, and because all of these procedures exhibited similarly unfavorable early reoperation rates, this explanation seems unlikely. The concordance between the 1-year ETV success rates reported herein and the observations of Lam et al., who published the only other population-based study of ETV outcomes in the literature, supports the methodology of the current study. ${ }^{14}$

\section{Conclusions}

Outcomes of shunt surgery for the treatment of hydrocephalus in the United States are worse than what is reported in the clinical research literature. The great preponderance of surgery for hydrocephalus is performed in adults and the elderly. There is an urgent need for basic science research, technical innovation, and quality improvement in the management of hydrocephalus, and this mandate must be borne by the entire profession of neurosurgery.

\section{Acknowledgments}

Allison LeHanka received support from the Nemours Summer Undergraduate Research Program.

\section{References}

1. Healthcare Cost and Utilization Project. Introduction to the HCUP Nationwide Readmissions Database (NRD) 20102015. Agency for Healthcare Research and Quality; 2017.

2. Chern JJ, Bookland M, Tejedor-Sojo J, et al. Return to system within 30 days of discharge following pediatric shunt surgery. J Neurosurg Pediatr. 2014;13(5):525-531.

3. Donoho DA, Buchanan IA, Patel A, et al. Early readmission after ventricular shunting in adults with hydrocephalus: a Nationwide Readmission Database analysis. World Neurosurg. 2019;128:e38-e50.
4. Al-Tamimi YZ, Sinha P, Chumas PD, et al. Ventriculoperitoneal shunt 30-day failure rate: a retrospective international cohort study. Neurosurgery. 2014;74(1):29-34.

5. Anderson IA, Saukila LF, Robins JMW, et al. Factors associated with 30-day ventriculoperitoneal shunt failure in pediatric and adult patients. J Neurosurg. 2018;130(1):145-153.

6. McGirt MJ, Leveque JC, Wellons JC III, et al. Cerebrospinal fluid shunt survival and etiology of failures: a seven-year institutional experience. Pediatr Neurosurg. 2002;36(5):248255.

7. Piatt JH Jr. Thirty-day outcomes of cerebrospinal fluid shunt surgery: data from the National Surgical Quality Improvement Program-Pediatrics. J Neurosurg Pediatr. 2014;14(2):179-183.

8. Kulkarni AV, Drake JM, Mallucci CL, et al. Endoscopic third ventriculostomy in the treatment of childhood hydrocephalus. J Pediatr. 2009;155(2):254-259.e1.

9. Drake JM, Kestle JR, Milner R, et al. Randomized trial of cerebrospinal fluid shunt valve design in pediatric hydrocephalus. Neurosurgery. 1998;43(2):294-305.

10. Kestle JR, Drake JM, Cochrane DD, et al. Lack of benefit of endoscopic ventriculoperitoneal shunt insertion: a multicenter randomized trial. J Neurosurg. 2003;98(2):284-290.

11. Marguerie M, Cochrane DD. Thirty-day outcomes of cerebrospinal fluid shunt surgery: modeling using data from the National Surgical Quality Improvement Program-Pediatrics. Letter. J Neurosurg Pediatr. 2016;18(4):509-510.

12. Cochrane DD, Kestle J. Ventricular shunting for hydrocephalus in children: patients, procedures, surgeons and institutions in English Canada, 1989-2001. Eur J Pediatr Surg. 2002;12(suppl 1):S6-S11.

13. Cochrane DD, Kestle JR. The influence of surgical operative experience on the duration of first ventriculoperitoneal shunt function and infection. Pediatr Neurosurg. 2003;38(6):295301.

14. Lam S, Harris D, Rocque BG, Ham SA. Pediatric endoscopic third ventriculostomy: a population-based study. J Neurosurg Pediatr. 2014;14(5):455-464.

\section{Disclosures}

The authors report no conflict of interest concerning the materials or methods used in this study or the findings specified in this paper.

\section{Author Contributions}

Conception and design: Piatt. Acquisition of data: both authors. Analysis and interpretation of data: both authors. Drafting the article: Piatt. Critically revising the article: both authors. Reviewed submitted version of manuscript: both authors. Approved the final version of the manuscript on behalf of both authors: Piatt. Statistical analysis: Piatt. Administrative/technical/ material support: Piatt. Study supervision: Piatt.

\section{Correspondence}

Joseph Piatt: Nemours/Alfred I. duPont Hospital for Children, Wilmington, DE.jpiatt@nemours.org. 